\title{
Counterfeit drugs and medical devices in developing countries
}

This article was published in the following Dove Press journal:

Research and Reports in Tropical Medicine

24 March 2014

Number of times this article has been viewed

\section{Beverley D Glass}

School of Pharmacy and Molecular Sciences, James Cook University,

Townsville, QLD, Australia
Correspondence: Beverley D Glass School of Pharmacy and Molecular Sciences, James Cook University, I James Cook Drive, Townsville, QLD 48I I, Australia

$\mathrm{Tel}+6$ I 7478 I 6423

Fax $+6|7478| 5356$

Email beverley.glass@jcu.edu.au
Abstract: The World Health Organization has reported that counterfeit medicines potentially make up more than $50 \%$ of the global drug market, with a significant proportion of these fake products being encountered in developing countries. This occurrence is attributed to a lack of effective regulation and a weak enforcement capacity existing in these countries, with an increase in this trade resulting from the growing size and sophistication of drug counterfeiters. In addition, due to both cost and lack of availability of medicines, consumers in developing countries are more likely to seek out these inexpensive options. The World Health Organization is mindful of the impact of counterfeit drugs on consumer confidence in health care systems, health professionals, the supply chain, and genuine suppliers of medicines and medical devices. Antibiotics, antituberculosis drugs, and antimalarial and antiretroviral drugs are frequently targeted, with reports of $60 \%$ of the anti-infective drugs in Asia and Africa containing active pharmaceutical ingredients outside their pharmacopoeial limits. This has obvious public health implications of increasing drug resistance and negating all the efforts that have already gone into the provision of medicines to treat these life threatening conditions in the developing world. This review, while focusing on counterfeit medicines and medical devices in developing countries, will present information on their impact and how these issues can be addressed by regulation and control of the supply chain using technology appropriate to the developing world. The complexity of the problem will also be highlighted in terms of the definition of counterfeit and substandard medicines, including gray pharmaceuticals. Although this issue presents as a global public health problem, outcomes in developing countries where counterfeit drugs to treat malaria, tuberculosis, and human immunodeficiency virus/acquired immunodeficiency syndrome not only result in drug resistance, but a number of deaths from the untreated disease, is in stark contrast with the developed world, where lifestyle drugs such as sildenafil $\left(\right.$ Viagra $\left.^{\circledR}\right)$ are most commonly counterfeited.

Keywords: counterfeit, medicines, devices, developing countries, drug resistance, public health

\section{Introduction}

Product counterfeiting is increasing worldwide, both in terms of the volume, level of sophistication, and in the number the countries affected, both in the developed and developing world. Despite the diversity of products counterfeited, counterfeiters are often referred to as a homogeneous group. Staake et a $1^{1}$ have however classified counterfeiters into five groups: 1) disaggregators; 2) imitators; 3) fraudsters; 4) desperados; and 5) smugglers, to better address the issue of counterfeiting in the market. These groups were classified according to the visual and functional quality of the counterfeit products, in addition to product complexity. The disaggregator group encompasses counterfeit products with an average visual quality, medium functional 
quality, and low to medium product complexity, while the imitators represent those products with the highest visual and functional quality and product complexity. The term imitator is appropriately used in this case, as these counterfeits closely resemble the genuine products. Although the smuggler group, which includes products with average to high visual and functional quality and medium complexity, resembles the imitator group, the major difference is the circumvention of taxes by this group. The fraudster group includes those products of high visual but low functional quality, which because of their medium complexity are likely to pass as genuine. Because of the deception involved, and the potential financial loss to the buyer, the term fraudster was deemed appropriate. For pharmaceutical products, which represent $9 \%$ of the sample in this study, all counterfeiters were classified as desperados. This group represents products where the visual quality is medium to high, while the functional quality and product complexity is low. They are said to pose a severe threat to consumers and as such, this places the counterfeiters into conflict with enforcement agencies such as regulators, with the term desperados relating to the unscrupulous nature of this group. Counterfeiters have unfortunately also evolved over time with the transformation of a counterfeit producer to an illicit manufacturer occurring, which is particularly relevant to counterfeited pharmaceutical products.

The term counterfeit drug has been defined differently in different countries limiting both the exchange of information between countries and a real understanding of the extent of the problem globally. To address this problem, the World Health Organization (WHO) has proposed that a counterfeit medicine (branded or generic products) be defined as one which is deliberately and fraudulently mislabeled with respect to identity and/or source. ${ }^{2}$ This however should not be confused with the term substandard medicines, which may be described as genuine drug products which do not meet the required quality specifications. "Gray pharmaceuticals" is a term recently used for the marketing of competitive brands by illicit profiteers who do not have regulatory approval.

Counterfeit products are those: 1) without active pharmaceutical ingredients (APIs), including the wrong ingredients, which may or may not be toxic. In this case, the API is often replaced by inexpensive substitutes such as flour, curcuma, or cassava in oral formulations and water in injections. Even more of a problem is that these products may contain toxic or pathogenic chemical impurities, which have potentially lethal consequences, with an example being methanol detected in a counterfeited amoxicillin injection; ${ }^{2}$ ) with incorrect quantities of these APIs, where these products usually contain less than the stated amount. Examples here are less expensive or outdated drugs, which may be repackaged, such as diazepam syrup which was sold as cotrimoxazole syrup in Nigeria and erythromycin sold as the antimalarial, artesunate, in southeast Asia. Another example is praziquantel, used against schistosomiasis, where the forgery was detected because each tablet should have contained $600 \mathrm{mg}$ of API and the tablets only weighed $480 \mathrm{mg}$ in total. In addition, the leaflet was written in poor English, without any manufacturer identification; 3 3) with fake or counterfeit packaging, where the packaging may be copied, or in some cases modified, to escape prosecution for infringing intellectual property. ${ }^{2}$

The United States Food and Drug Administration have reported on the existence of counterfeit and substandard medicines in both developed and developing countries, with $25 \%$ (range between 10\%-30\%) of the counterfeit and substandard medicines being consumed in developing countries, including Latin America, southeast Asia, or sub-Saharan Africa. ${ }^{4}$ Evidence from 17 countries $^{5}$ has revealed that there is a relationship between price and the poor quality of medicines. The purchasers of these products are also likely to suspect that they are of low quality, if in addition to low price, the product is generic and available from a pharmacy or outlet, with a poor appearance. It must however be stated that even if all these factors are present, it cannot be assumed that the products are counterfeit. These findings do present information on the economics of poor quality drugs and the extent to which consumers can draw accurate conclusions relating quality to both price and the appearance of the pharmacy. Unfortunately the poor consumer in the developing world, who will inevitably have a low income and limited literacy, will still choose to purchase on the assumption that it is better than no treatment at all. These findings concur with those of Furnham and Valgeirsson ${ }^{6}$ who reported on the effect of life values and materialism on buying counterfeit products. Their study was conducted on a sample of educated British people who were willing to buy counterfeit pens and clothing for a good price. They were however not prepared to do so in the case of medicines. Stumpf and Chaudhry ${ }^{7}$ also explored the effect of country on the counterfeit trade. In 2006, most (54\%) of the counterfeit drugs detected were manufactured in India, with China manufacturing $21 \%$ and Hong Kong manufacturing $10 \%$. The site of manufacture for these drugs is reported to take place more readily in countries which themselves neither have good purchasing practices nor good regulation. However, the fact that there are few published data limits the accurate estimation of the extent of the problem and its impact on public health. Although the incidence of 
counterfeit medicines is low in the developed world, there has been an increase by $400 \%$ in the number of these drugs identified from 2005 to 2010 in Europe. ${ }^{8}$ The fact that this trade is said to be 25 times more lucrative than that of heroin places a perspective on and highlights the magnitude of this problem. $^{8}$

Counterfeit medicines, unfortunately, are not a new concept, with trading in these counterfeit medicines, sometimes referred to as fake medicines, beginning several millennia ago. ${ }^{8}$ In fact, it is ironic today that antibiotics are the most counterfeited medicines, occupying a $28 \%$ share of this market, when fake cinchona bark was reported as a crisis as early as the 1600 s and fake quinine in the 1800 s. $^{9}$ These counterfeit antibiotics include mainly the "old" antibiotics such as beta-lactams and quinolones, which have been commonly used for years. Amoxicillin is reported to be the most counterfeited API in the world, and the cause of treatment failure in Papua New Guinea. ${ }^{10}$ Counterfeit anti-infective drugs were first reported over 25 years ago. ${ }^{11}$ Until recently, the published research in this area has been limited, with much of the information, especially in developing countries, found in the gray literature. In fact, most of the current literature is related to analytical approaches to detect counterfeit medicines, which due to cost and expertise required, have limited application in developing countries.

Dosage forms for oral administration, eg, tablets, syrup, and capsules are those most commonly counterfeited (77\%), as opposed to injectable formulations $(17 \%) .{ }^{10}$ This obviously relates to the level of sophistication of the equipment required to produce injectable formulations. ${ }^{10}$

A comprehensive review on understanding and fighting the counterfeit medicine market by Dégardin et al ${ }^{12}$ highlights the situation worldwide and proposes solutions to limit this phenomenon. Almuzaini et al ${ }^{13}$ have however also presented a systematic review of the literature to explore the evidence available, not only for counterfeit medicines but also for all poor quality medicines, whether counterfeit or substandard.

\section{Counterfeiting of drugs - why?}

WHO estimated as far back as 1991 that half of the world's population at that stage did not have regular access to essential drugs, with this number reducing to $33 \%$ in sub-Saharan Africa. ${ }^{14}$ Although counterfeit drugs are an important issue in Africa, there are also a number of other constraints to the regular supply of essential drugs, including geographic location, logistics, ensuring the integrity of the supply chain, and financing the supply of essential drugs. It must also be noted that some of these constraints also play a role in compounding or impacting the issue of counterfeit drugs in Africa. ${ }^{14}$ There are a number of factors which make medicines a viable and attractive option for counterfeiters, particularly in the developing world. These factors and their importance in developing countries as well as the risk rated as mild, moderate, or high, are listed in Table 1. Drug products lacking in quality, safety, and efficacy, and that are not under regulatory control, may result in prolonged therapy, promote resistance, and cause adverse effects, which are then not reported on or monitored. This has potential to significantly impact on global public health.

\section{Impact of counterfeit medicines and devices Developing countries}

The International Medical Products Anti-Counterfeiting Taskforce (IMPACT) was established in February 2006, to coordinate efforts to address the issue of counterfeit drugs, ${ }^{15}$ as this subject has taken on a new dimension within the international health community. Mitigating a macroeconomic pandemic has attracted the attention of prominent members of the public health community who have commented on the potential outcomes of treating, eg, human immunodeficiency virus/acquired immunodeficiency syndrome (HIV/AIDS) patients with counterfeit drugs. ${ }^{16}$ IMPACT, led by WHO, had plans to focus on the following key areas: legislative and regulatory infrastructure, regulatory implementation,

Table I Factors affecting the counterfeiting of drugs

\begin{tabular}{|c|c|c|c|}
\hline Factor & Explanation & $\begin{array}{l}\text { Importance } \\
\text { in developing } \\
\text { country }\end{array}$ & Risk \\
\hline $\begin{array}{l}\text { Government } \\
\text { will and } \\
\text { commitment }\end{array}$ & $\begin{array}{l}\text { Drugs should not be treated } \\
\text { as other commodities due } \\
\text { to effect on public health }\end{array}$ & & $*$ \\
\hline $\begin{array}{l}\text { Drug } \\
\text { regulatory } \\
\text { body }\end{array}$ & $\begin{array}{l}\text { Legislation does not exist } \\
\text { WHO member states: } \\
\text { a) } 20 \% \text { - well developed } \\
\text { b) } 50 \% \text { - varied development } \\
\text { c) } 30 \% \text { - no or nonfunctional } \\
\text { regulation }\end{array}$ & & $* *$ \\
\hline $\begin{array}{l}\text { Demand } \\
\text { exceeds } \\
\text { supply }\end{array}$ & $\begin{array}{l}\text { Health care system lack of } \\
\text { supply of medicines due to: } \\
\text { a) Poverty } \\
\text { b) Illiteracy } \\
\text { c) Rural locations }\end{array}$ & $\begin{array}{l}\text { Creates a market } \\
\text { for criminally } \\
\text { minded people }\end{array}$ & $* * *$ \\
\hline High prices & Price differentials & $\begin{array}{l}\text { Supply chain, } \\
\text { poverty }\end{array}$ & $* *$ \\
\hline
\end{tabular}

Notes: *Denotes risk rated as mild; **denotes risk rated as moderate; ***denotes risk rated as high. Data from $\mathrm{WHO}{ }^{2}$

Abbreviation: WHO, World Health Organization. 
enforcement, technology, and communication. Table 2 presents a summary of the impact of counterfeit medicines for people in developing countries.

\section{Antibiotic drugs}

Acquired bacterial resistance is common in developing countries, with this resistance increasing to first line broad spectrum agents. This is of particular concern as these agents are inexpensive and given the budgetary constraints within developing countries, are often the only affordable drugs. It is also worrying how rapidly resistance has emerged to the newer agents, such as the fluoroquinolones. This has been attributed to the misuse of antibiotics by physicians, unskilled practitioners, and the public. ${ }^{18}$ In developing countries, counterfeit medicines are only one aspect of poor quality antibiotics, with other issues including a lack of adherence

Table 2 Impact of counterfeit medicines for developing countries

I. Increased mortality and morbidity: due to ingredients substituted for the API, which are lethal. In the past it has been assumed that these ingredients were inert, eg, starch or lactose. Paracetamol adulterated with diethylene glycol, a renal toxin and a cheaper substitute for propylene glycerol or glycerol, caused the death of a number of children in various developing countries, including Bangladesh. ${ }^{17}$

2. Drug resistance: due to subtherapeutic amounts of API in the drug product. In developing countries this is particularly relevant to the supply of antibiotics, and antimalarial and antiretroviral drugs, resulting in the emergence of drug resistant pathogens. Combination therapy for TB, HIVIAIDS, and malaria limited by poor quality artemisinin derivatives and similarly, poor quality TB drugs does not only result in treatment failure, but increases the incidence of drug resistance.

3. Reduced confidence in the health system: due to the consequences of these counterfeit medicines, often among patients who were skeptical of these essentially "Western" systems at the outset. This also results in an increased workload for health professionals and health outlets such as clinics and pharmacies to attempt to restore this confidence.

4. Economic consequences: for patients and their families, the country, and the providers of genuine medicines, due to a workforce which is often too ill to work or care for their families.

5. Adverse effects: due to incorrect ingredients, where the effects may vary from being unexpected (eg, when cotrimoxazole contains diazepam) to causing allergic reactions (eg, artesunate tablets containing chloramphenicol). In addition, it cannot be assumed that counterfeit products containing APls will be subtherapeutic, as in some cases, they contain more than the stated amount and for those drugs with narrow therapeutic indices, this increases the potential for adverse effects.

6. Wastage: financially due to the efforts of governments both in the developing countries, who have attempted to make these medicines available to patients, and to those in the developed world, who often sponsor the provision of these drugs to control and/or eradicate diseases such as TB, malaria, and HIVIAIDS.

Note: Data from Newton et $\mathrm{al}^{8}$ and Wertheimer and Norris. ${ }^{16}$

Abbreviations: APIs, active pharmaceutical ingredients; HIV/AIDS, human immunodeficiency virus/acquired immunodeficiency syndrome; TB, tuberculosis. and monitoring, degraded antibiotics often due to inadequate storage in both pharmacies and in the supply chain, expired antibiotics distributed from developed countries, and bioinequivalent antibiotics. Between 1981 and 1995, resistance to ampicillin, tetracycline, sulfonamides, chloramphenicol, fluoroquinolones, isoniazid, streptomycin, and rifampicin was shown to be increasingly prevalent across the following developing and tropical countries: Bangladesh, Brazil, Rwanda, Thailand, India, Kenya, and Morocco. ${ }^{18}$ As an indication of the problem of counterfeiting in relation to antibiotics, it has been reported that counterfeit drugs account for $5 \%$ of antibiotics sold worldwide, with this percentage a lot higher in developing countries. ${ }^{9}$ Counterfeiting of antibiotics in developed countries is a rarity, eg, in the French health care network there has been no reported counterfeiting of antibiotics. This has been attributed to effective control of marketing, the supply chain, and strict enforcement by customs. ${ }^{9}$ These counterfeit drugs in developing countries only compete favorably in these markets because of the lack of availability of analytical laboratories and because a substantial proportion of the drugs in these countries are generic, often resulting in the counterfeit drugs going undetected.

Because countries of sub-Saharan Africa are highly affected by infectious disease, and because of economics, corruption, and lack of regulation and control they are an obvious target for counterfeiters. The unfavorable outcome of this is that they account for $50 \%$ of the deaths due to infectious diseases, even though these countries only have $12 \%$ of the world population. ${ }^{18}$ There is also a discrepancy in the availability of health care between rural and urban or metropolitan regions. Although this has been described for India and China, this is true for most countries, often even those in the developed world. Metropolitan areas are less concerned with counterfeit drugs, and there are in fact similarities between these urban zones in developing countries and those countries in the developed world. ${ }^{18}$

Antibiotics are reported to be counterfeited according to chemical class such as beta-lactams and the type of formulation (77\% for oral intake) and are often presented in a counterfeited package. Antibiotic counterfeiting has implications for the individual and the collective population, with obvious industrial and economic consequences. In studies conducted in Burma, Cameroon, Vietnam, Cote d'Ivoire, and Nigeria, between $8 \%$ and $35 \%$ of the anti-infectives were found to be counterfeit, in most cases with the API content being out of the pharmacopoeial limits, with no API present, and in the case of the antimalarials, chloroquine being substituted for quinine. ${ }^{18}$ 


\section{Antimalarial drugs}

The prevalence of malaria in tropical countries results in antimalarials being the most widely taken drug and therefore often described as "blockbuster" drugs for counterfeiters. Two thirds of the available antimalarials are reported to be counterfeited, eg, for mefloquine and artesunate found in Cambodia in 1998 , up to $71 \%$ and $60 \%$, respectively, were reported to be fake. ${ }^{19}$ In addition, chloroquine was reported to be substituted for artesunate and mefloquine tablets contained sulphadoxine-pyrimethamine. Since 1998, between 38\% and $53 \%$ of the artesunate blister packages were reported to contain no API, with some counterfeits containing only minimal amounts of artesunate. In Cambodia, an effort has been made to address the quality of antimalarials in both the public and the private health sectors, where $79 \%$ of the 451 drug samples collected in 2006 were not registered with the Cambodian Department of Drugs and Food. ${ }^{19}$ This resulted in the National Malaria Control Program taking action and attempting to alert both the population and the health departments about these counterfeit antimalarials. ${ }^{19}$ Although the National Malaria Control Program has promoted the use of good quality antimalarials through both the private and public sectors, there was a concern that over $82 \%$ of the population acquired these products from the private rather than public sector. In addition, for those people living in remote areas, the problem is exacerbated because they are less informed and there is increased tendency for people in these locations to buy cheaper drugs from local outlets. ${ }^{19}$ Newton et $\mathrm{a}^{11}$ have continued to highlight that counterfeit medicines have the most profound effect on disadvantaged people in poor countries, usually in the developing world. Although they addressed anti-infectives in general, particular attention was paid to antimalarials as they are the most widely taken drugs in tropical countries. ${ }^{11}$ These authors recommend that to combat the counterfeiters, good quality anti-infectives should be available at an affordable price. However, to achieve this, there is a need for adequate information on the quality of the drug supply in the "real life" situation. Although clinical trials to determine the appropriate antimalarials for use in particular countrie ${ }^{20}$ have been undertaken, unfortunately this is of little use if the supply of quality antimalarial drugs is not maintained and monitored.

Newton et $\mathrm{a}^{21}$ reported that the efficacy of artesunate as a key treatment for multidrug resistant malaria in mainland southeast Asia was being compromised by the widespread occurrence of counterfeit artesunate tablets. The inaction of international organizations, such as WHO, was reported to be due to a lack of resources and regulation, but more importantly, also due to a lack of knowledge of the impact of the fake artesunate. ${ }^{22}$ This is due to the many deaths of people in rural locations not being attributed to fake antimalarials. ${ }^{22}$

In southeast Asia from 2002 to 2003, up to 53\% of the artesunate in blister packages was reported to be fake, with counterfeit types classified by packaging and fake holograms encountered in the People's Republic of China. ${ }^{23}$ This highlighted the increasing level of sophistication of the counterfeiters. Because it is one of the most threatened foci of malaria, the Greater Mekong subregion has also been the subject of an investigation into the emergence of artemisinin resistance, with the existence of counterfeit or substandard medicines being attributed to worsening the situation. ${ }^{23}$ It has been reported that countries in the Greater Mekong subregion face a greater challenge when compared to African countries in combating the threat of counterfeit antimalarials. ${ }^{23}$ Even though there are superior legislative procedures in countries such as Thailand, a study in 80 outlets revealed that $15.4 \%$ of the artesunate, $11.1 \%$ of the chloroquine, and $29.4 \%$ of the quinine were substandard. ${ }^{23}$

In 2012, Nayyar et $\mathrm{al}^{24}$ reviewed the chemical analyses and packaging of antimalarial drugs to identify poor quality antimalarials in southeast Asia and sub-Saharan Africa. Although the global burden of malaria has reduced in the past decade, there is concern that these poor quality antimalarials are likely to put into jeopardy the progress that has been made in these regions in eliminating malaria. Results achieved were similar for the two regions, especially in relation to failed packaging analysis. For southeast Asia (sub-Saharan Africa), $46 \%$ (35\%) failed the chemical analyses, $36 \%$ (35\%) failed packaging analysis, and overall, $36 \%(20 \%)$ were classified as falsified. Despite a multifaceted approach needed to address the issue, empowering of regulatory agencies to protect drug supply is seen as key to addressing the problem. ${ }^{24}$

Counterfeiting of antimalarials poses a significant public health problem worldwide. Rapid, reliable, and inexpensive methods are needed to screen for the quality of these antimalarial drugs. Chemical characterization of counterfeit antimalarials involves investigating both their drug content and dissolution. It is important, especially in developing countries where advanced techniques are not available, that simple and affordable field methods be used to determine drug content. Raman spectrometry, which does not require sample preparation and allows analysis through a blister pack, presents a good option for the determination of drug content. Limitations of this method include a lack of sensitivity and the requirement that the practical utility of the portable Raman unit in the field be further investigated..$^{25}$ 
Green et $\mathrm{al}^{26}$ put forward the combined use of refractometry and colorimetry as an appropriate method for field use to assess antimalarial drug quality. Colorimetry makes use of color changes from specific chemical reactions, does not require toxic organic solvents, and makes use of a portable battery powered photometer. A refractometer, which is inexpensive and portable, also provides a rugged measure of the refractive index of a drug solution, a common physical property which can be used to identify counterfeits. Results from method bias, sensitivity, specificity, and accuracy relative to high performance liquid chromatography indicated that these techniques provide a simple, accurate, and affordable means to determine drug quality in resource poor settings and are thus appropriate for use in developing countries. Newton et $\mathrm{ll}^{11}$ also highlight the importance of dissolution studies to provide information on in vivo bioavailability. Poor drug dissolution may not be due to the incorrect amount of API, but be due to the incorrect excipients and/or poor manufacturing procedures. Dissolution, which reflects drug absorption, bioavailability, and ultimately efficacy, is thus critical to ensuring the quality of antimalarial drugs. ${ }^{11}$

\section{Antiretroviral and antituberculosis drugs}

The impact of counterfeit drugs has the potential to escalate toward a macroeconomic pandemic if the emergence of drug resistance and mutation of viruses, especially in the treatment of HIV/AIDS occurs, resulting in populations which are too ill to work in addition to overwhelming the health resources of their respective countries. ${ }^{16}$ Although there are not sufficient data to confirm whether resistance to antiretrovirals (ARVs) is due to counterfeit drugs or natural resistance, increasing resistance has been reported in the United Kingdom, Spain, and Brazil. In India, a high prevalence of HIV-1 and HIV-2 coinfections has resulted in it being necessary for more expensive ARV therapies to be used. ${ }^{16}$ Trade in counterfeit drugs is responsible for increasing drug resistance among the infectious diseases, including tuberculosis and HIV/AIDS. A study in Botswana, reported in 2005, found that 315 of the drugs used in tuberculosis treatment were substandard, either containing toxic ingredients or no API. ${ }^{16}$ It is ironic that the many millions of dollars contributed by governments of developing countries from their limited resources and that are donated from developed countries to treat HIV/AIDS and tuberculosis are attracting criminals who are playing a role in setting this pandemic in motion. It has also been reported by $\mathrm{Ahmad}^{27}$ that antidepressants are being sold as ARVs in the Democratic Republic of Congo. Fluvoxamine, an antidepressant and cyclobenzaprine hydrochloride, and a muscle relaxant, has been labeled as Triomune ${ }^{\circledR}$, which is a combination of stavudine, lamivudine, and nevirapine, and Duovir $^{\circledR}$, a combination of zidovudine and lamivudine, two commonly prescribed ARV brands. The prevalence of HIV/ AIDS in the Democratic Republic of Congo, which has been made worse by the long civil war, ranges from $5 \%$ to $15 \%$, with many people relying on counterfeit medicines, because of price and the shortage of good quality ARVs. ${ }^{27}$ Fears et al ${ }^{28}$ have also reported on the re-emergence of tuberculosis in the European Union (EU) and its failure to respond to the global tuberculosis threat. They also advocated for a humanitarian role for the EU to support tuberculosis control in developing countries. $^{28}$

\section{Medical devices}

Medical devices (MDs) and in vitro diagnostics (IVDs) are a wide range of products and include those simply used as a tongue depressor to very complex equipment, with IVDs used to examine human specimens in vitro. Although the primary action of these devices is not pharmacological, they are however not exempt from counterfeiting with WHO reporting ${ }^{29}$ in 2010 that over $8 \%$ of these devices in circulation were counterfeit. The market in these devices is set to increase by $50 \%$ in 2014, which highlights their increasing role in health care. However despite this, there are significant differences between developed countries such as Australia, Canada, the EU, and the United States and resource limited developing countries, not only in their quality but in the ability of countries to access these products. Again there is a tension between the definitions for counterfeit and substandard devices. Counterfeit devices have been defined in line with counterfeit products to be those which are deliberately mislabeled, whereas those substandard IVDs do not meet specifications and/or contain labeling errors. Mori et $\mathrm{al}^{30}$ undertook a detailed review of the literature and reported on low quality MDs/IVDs in resource limited countries. Table 3 presents a summary of their findings, giving examples of MDs/IVDs all performing poorly in relation to a reference product. It is important to note that climatic conditions do have some effect on the performance of these products, with poor performance often found during use in tropical conditions. A further limitation was the inability to distinguish whether performance of the MD/IVD was related to quality or poor practices.

These data are however limited by the fact that there are very few reports in the scientific literature, with much of the information from the gray literature, especially in relation to HIV/AIDS and Dengue test kits. In addition, the poor 
Table 3 Examples of quality issues related to medical devices and in vitro diagnostics

\begin{tabular}{|c|c|c|c|}
\hline Test type & Area & Quality & Date/reference \\
\hline Microkeratomes & Asia & $\begin{array}{l}\text { Manufacturer } \\
\text { specifications }\end{array}$ & $200 I^{31}$ \\
\hline $\begin{array}{l}\text { Blood glucose } \\
\text { meter }\end{array}$ & Africa & $\begin{array}{l}\text { Sensitivity - } \\
\text { tropics }\end{array}$ & $2003^{32}$ \\
\hline $\begin{array}{l}\text { Boehringer } \\
\text { Mannheim-lactate } \\
\text { test strips }\end{array}$ & Asia & $\begin{array}{l}\text { Tampered } \\
\text { expiry date }\end{array}$ & $2004^{33}$ \\
\hline Antibiotic discs & Asia & $\begin{array}{l}\text { Inconsistent } \\
\text { results }\end{array}$ & $2006^{34}$ \\
\hline Antiseptic & South America & $\begin{array}{l}\text { Substandard } \\
\text { efficacy }\end{array}$ & $2006^{35}$ \\
\hline Antibiotic discs & South America & $\begin{array}{l}\text { Inconsistent } \\
\text { results }\end{array}$ & $2007^{36}$ \\
\hline Fuchsin dye & Africa/Asia & $\begin{array}{l}\text { Impurity in } \\
\text { powders }\end{array}$ & $2009^{37}$ \\
\hline
\end{tabular}

Note: Data from Mori et al. ${ }^{30}$

practices in terms of poor laboratory practices and lack of training, including the ability to interpret results will also play a role in concealing inaccurate diagnoses due to poor quality IVDs. ${ }^{38}$

\section{Addressing the issue of counterfeit medicines \\ Regulation}

Adulterated medicines were reported to exist as early as the fourth century BC, with warnings to people about the harmful nature of these medicines. Changes over the years have seen increases in the expertise of the counterfeiters and the extent of the problem. Seear ${ }^{39}$ has highlighted that counterfeiting is only one cause of poor drug quality and that reliable research into the extent of counterfeiting is lacking with no randomized studies of drug quality undertaken in either China or India. Despite all the technological advances, this problem still exists and has prompted WHO to put out a set of guidelines to inform the development of national strategies to combat counterfeit medicines, in addition to suggested approaches to detecting and monitoring these drugs, including staff training..$^{40}$ Much of these efforts have been limited at the international level by the confusion around the definition of counterfeit medicines. This has been attributed to the inability to distinguish between intellectual property rights, trademark protection, and authenticity and correct representation of drug content and quality. ${ }^{41}$ The requirement is that this global threat requires solutions which are global, regional, and national and there is some frustration that despite the establishment of IMPACT in $2006,{ }^{15}$ little has been achieved.
The Medicrime Convention was drafted by the Council of Europe in 2010 to include for the first time an international standard criminalizing the manufacture and distribution of counterfeit medicines. ${ }^{15}$ This approach is limited as this standard can impede the introduction of new generic drugs into these markets, criminalize manufacturers for legitimate mistakes, and most importantly, it is distrusted by developing countries, especially India and Brazil. These views have been summarized by Bate and Attaran ${ }^{42}$ who indicate that these European officials lack the credibility to effect a global drug treaty, which should have been the responsibility of WHO, through the global initiative, IMPACT.

Frustrations raised by developing countries, especially India and Brazil, have included: the lack of accountability of IMPACT to WHO, the role of WHO as a public health organization and not an enforcement agency for intellectual property law, the fact that member states did not endorse WHO to be a secretariat of IMPACT, and the need for WHO support of developing countries. ${ }^{43}$ There was also concern about the lack of transparency in terms of the involvement of IMPACT with big pharma and its role in enforcing intellectual property rights rather than serving the purpose of public health. This inability to maintain balance between intellectual property and drug quality has resulted in IMPACT moving its secretariat from Geneva to Italy ${ }^{43}$ and thus in 2012, members welcomed the establishment of the new member state mechanism (MSM), ${ }^{44} \mathrm{a}$ governance structure to address the issue of poor quality medicines.

The 65th World Health Assembly in 2012 put forward new tools to combat what they defined as substandard/spurious/ falsified/counterfeit medicines. ${ }^{45}$ Recommendations were to focus on the public health implications of these medicines whilst providing support for the establishment of the New Member States Mechanism ${ }^{45}$ within the framework of WHO to facilitate information exchange and foster international collaboration to combat these medicines. In addition, member states undertook to develop direction tools, build capacity, establish global monitoring systems, and more importantly, to assess risk in the allocation of resources taking into account their national context. Interestingly, a workshop was also held on the regulation of medical devices for the first time, with the outcome of suggested collaborations between regulatory authorities in developed countries with those countries with less developed systems. ${ }^{45}$

At a regional level, harmonization of medicine registration and regulatory activities are being addressed, eg, by the African Medicines Regulatory Harmonization Initiative. This 
initiative aims to use scarce resources to improve standards, including addressing the issue of poor quality and counterfeit drugs. ${ }^{46}$

The United States Pharmacopeial Convention has also undertaken to train medicine regulatory officers at a training center established in Ghana, so that African nations can address the issue of regulation of drugs in the region. ${ }^{47}$ Although the United States Pharmacopeial has contributed funding for this initiative, it is expected that the member countries, currently including Ghana, Ethiopia, Kenya, Senegal, Sierra Leone, and Nigeria will begin to contribute financially. These programs will include training in dossier evaluation, good manufacturing practice, and laboratory techniques. The plan to build a quality control laboratory, which will charge for services, has attracted the interest of local pharmaceutical industries, who due to their own lack of infrastructure see this as an opportunity to undertake the testing of their products. This training center is seen as providing an important opportunity for countries to share information on counterfeit medicines. ${ }^{47}$

At a national level, despite the growth in technology including screening devices in the field and the use of text messages by consumers, regulation continues to present a challenge in developing countries. A study was undertaken in Tanzania to identify whether reforms of pharmaceutical policy were undertaken to in fact improve efficiency or whether they just presented an opportunity for vested interests. ${ }^{48}$ Findings from the study highlighted the influence of politics on decision making at many levels of the reform process, with regulation remaining a challenge. There is a call on governments to limit the political influence on policy, in the interests of appropriate public health outcomes for the populations of developing countries. ${ }^{48}$

Despite all these efforts, ineffectual governance and divergent interests are reported by Mackey and Liang ${ }^{49}$ to be the reason for the limited surveillance of counterfeit medicines and the continuing global public health threat. Despite the fact that as early as 1988, the World Health Assembly of WHO called for global action on counterfeit medicines in the interest of medicine safety, arguments over terminology have detracted attention from the crisis and the threat to public health. These authors therefore have suggested the formation of an enhanced global health governance trilateral mechanism between the WHO, the United Nations Office of Drugs and Crime (UNODC), and Interpol to optimize both the strengths and resources of these organizations. This proposal has been made because of the lack of enforcement capabilities of the WHO, and their conflict between representing public health needs and that of intellectual property. UNODC and Interpol have been suggested as partners in the trilateral mechanism due to the need for effective engagement against the criminal networks involved in counterfeiting. Since UNODC ${ }^{50}$ previously engaged in global health by participating in HIV/AIDS prevention and specializes in establishing policy to combat transnational crime, this should provide WHO with the freedom to redirect its efforts toward the protection of patient safety to achieve an improved public health outcome.

\section{Quality}

Controlling the quality and limiting drug counterfeiting requires different strategies in developing countries as compared to the developed world. ${ }^{51}$ Anticounterfeit measures using the short messaging service verification system was effective in developing countries including Ghana, Nigeria, and Kenya, with an announcement in early 2012 that more than one million people had used this system to verify the authenticity of their medicines. ${ }^{51}$ Since labeling allows manufacturers to monitor different batches of product, radiofrequency identification (RFID) using electronic devices to track and identify items ensures that the supply chain not only becomes more secure, but also efficient. The limitation of the short messaging service technology is that unlike the RFID, it cannot be traced and therefore is exposed to the potential of cloning by the counterfeiters. Serialization presents the advantage of uniquely identifying every item with a serial number stored in the RFID tag or in a bar code, with verification of these codes to be undertaken at the point of purchase. This system has been successfully implemented in North America and the recommendation is for use in developing countries. ${ }^{51}$ It has been concluded that ensuring maximum traceability and authenticity through the use of this technology has contributed to the low level of drug counterfeiting in developed countries.

The expansion in the number of pharmaceutical manufacturers in China and India and in the developed world has increased. This expansion includes in Kenya, Uganda, and Nigeria to accommodate the growing demand for pharmaceuticals and is good in that it has driven down the price of these products. However, this benefit is only of value if these products are in fact therapeutically equivalent to the original products and their quality is comparable. Bate et $\mathrm{al}^{52}$ have determined the quality of 1,912 drug samples from countries with emerging economies using basic thin layer chromatography and disintegration tests (failure rate of $3.8 \%$ ). They then compared the results with those achieved using Raman spectroscopy (failure rate of 5.2\%). Their 
Table 4 Analytical techniques used to detect counterfeit medicines

\begin{tabular}{|c|c|c|c|c|}
\hline Technique & Description & Drugs & Limitations cost & Technology \\
\hline $\begin{array}{l}\text { Near-infrared } \\
\text { spectroscopy }^{54}\end{array}$ & $\begin{array}{l}\text { NIR is rapid and simple } \\
\text { Physical and chemical } \\
\text { testing }\end{array}$ & $\begin{array}{l}\text { Trimethoprim/ } \\
\text { sulfmethoxazole } \\
\text { Drotaverine } \\
\text { Metronidazole }\end{array}$ & $\begin{array}{l}\text { NIR systems routine in } \\
\text { laboratories but portable } \\
\text { NIR for onsite } \\
* *\end{array}$ & $\begin{array}{l}\text { Inclusion of } \\
\text { chemometric analysis } \\
*\end{array}$ \\
\hline $\begin{array}{l}\text { Near-infrared } \\
\text { spectroscopy }{ }^{55} \\
\text { chemometric analysis }\end{array}$ & $\begin{array}{l}\text { NIR spectra acquired } \\
\text { and compared to } \\
\text { reference spectra }\end{array}$ & $\begin{array}{l}\text { Spectra of drug } \\
\text { in packaging } \\
\text { Paracetamol tablets }\end{array}$ & $\begin{array}{l}\text { NIR systems spectrometer } \\
*\end{array}$ & $\begin{array}{l}\text { Reference spectra } \\
\text { Inclusion of } \\
\text { chemometric analysis } \\
*\end{array}$ \\
\hline $\begin{array}{l}\text { Near-infrared } \\
\text { spectroscopy } \\
\text { Multivariate } \\
\text { classification models }\end{array}$ & $\begin{array}{l}\text { NIR spectra acquired } \\
\text { and compared to } \\
\text { reference spectra }\end{array}$ & Artesunate tablets & $\begin{array}{l}\text { NIR system US } \$ 45,000-\text { a } \\
\text { lower cost silicon-based } \\
\text { instrument US } \$ 5,000 \\
* *\end{array}$ & $\begin{array}{l}\text { Portable NIR battery } \\
\text { powered } \\
\text { Training minimal after } \\
\text { calibrations - basic } \\
\text { computer skills } \\
\text { ** }\end{array}$ \\
\hline $\begin{array}{l}\text { Capillary } \\
\text { electrophoresis }{ }^{57}\end{array}$ & $\begin{array}{l}\text { Analyze compounds with } \\
\text { good selectivity; simple, } \\
\text { rapid, and reliable }\end{array}$ & $\begin{array}{l}\text { Quinine } \\
\text { Furosemide } \\
\text { Trimethoprim/ } \\
\text { sulfmethoxazole }\end{array}$ & $\begin{array}{l}\text { Cost of reagents and thus } \\
\text { analysis low and low cost } \\
\text { maintenance } \\
* *\end{array}$ & $\begin{array}{l}\text { Compared low cost } \\
\text { CE equipment to } \\
\text { conventional setup } \\
* *\end{array}$ \\
\hline $\begin{array}{l}\text { Liquid } \\
\text { chromatography }{ }^{58,59}\end{array}$ & $\begin{array}{l}\text { Analyze with good } \\
\text { specificity, accuracy, } \\
\text { precision }\end{array}$ & $\begin{array}{l}\text { Antibiotics } \\
\text { Ampicillin } \\
\text { Amoxicillin } \\
\text { Doxycycline } \\
\text { Antimalarials } \\
\text { Quinine } \\
\text { Chloroquine } \\
\text { Mefloquine }\end{array}$ & $\begin{array}{l}\text { Reagents costly and high } \\
\text { cost equipment } \\
\text { Advantage: } \\
\text { One method for a number } \\
\text { of drugs } \\
*\end{array}$ & $\begin{array}{l}\text { Highly trained } \\
\text { personnel, specialized } \\
\text { equipment/maintenance } \\
*\end{array}$ \\
\hline $\begin{array}{l}\text { Fast chemical } \\
\text { identification system } \\
60\end{array}$ & $\begin{array}{l}\text { Color reactions based } \\
\text { on functional groups/thin } \\
\text { layer chromatography }\end{array}$ & Macrolide antibiotics & $\begin{array}{l}\text { Simple, rapid, cost } \\
\text { effective for use onsite } \\
* * * \\
\text { Lacks sensitivity of LC to } \\
\text { identify the drug }\end{array}$ & $\begin{array}{l}\text { Equipment simple, } \\
\text { limited expertise } \\
\text { required } \\
\text { *** }\end{array}$ \\
\hline $\begin{array}{l}\text { Gas chromatography/ } \\
\text { mass spectrometry }{ }^{61}\end{array}$ & $\begin{array}{l}\text { Residual solvents higher } \\
\text { than genuine products - } \\
\text { also often toxic }\end{array}$ & $\begin{array}{l}\text { Sildenafil and } \\
\text { Tadalafil tablets }\end{array}$ & $\begin{array}{l}\text { High cost equipment but } \\
\text { rapid, simple to undertake } \\
*\end{array}$ & $\begin{array}{l}\text { Specialized equipment, } \\
\text { limited training } \\
\text { required/maintenance } \\
\text { ** }\end{array}$ \\
\hline $\begin{array}{l}\text { Raman microscopy } \\
\text { and } 2 \mathrm{D} \text { correlation } \\
\text { spectroscopy }\end{array}$ & $\begin{array}{l}\text { Chemically analyze the } \\
\text { box colorants and visual } \\
\text { inspection }\end{array}$ & $\begin{array}{l}\text { Packaging } \\
\text { Tadalafil tablets }\end{array}$ & $\begin{array}{l}\text { Raman microscope, high } \\
\text { cost equipment } \\
*\end{array}$ & $\begin{array}{l}\text { Specialized equipment, } \\
\text { trained personnel } \\
\text { required/maintenance } \\
*\end{array}$ \\
\hline Calorimetry ${ }^{63}$ & $\begin{array}{l}\text { Reflectance visible } \\
\text { spectrum of solid material }\end{array}$ & $\begin{array}{l}\text { Packaging Sildenafil } \\
\text { tablets }\end{array}$ & $\begin{array}{l}\text { Colorimeter } \\
\text { Low cost } \\
\text { Limitations: } \\
\text { Reference library } \\
\text { Low precision for convex } \\
\text { tablets } \\
* * *\end{array}$ & $\begin{array}{l}\text { Simple equipment, easy } \\
\text { to operate, limited } \\
\text { maintenance } \\
* * *\end{array}$ \\
\hline
\end{tabular}

Notes: Cost is designated as: $* * *$ affordable; $* *$ medium affordability; and *not affordable. Equipment and expertise (technology) is designated by the level of applicability to developing countries as: ***applicable; **medium applicability; and *not applicable.

Abbreviations: CE, capillary electrophoresis; LC, liquid chromatography; NIR, near-infrared spectroscopy.

findings indicated that the failure rate of drugs produced by African companies was $8.3 \%$ and that these failures were relatively higher amongst antimalarials than antibiotics. This study highlights the problem in Africa, and is attributed to poor manufacturing locally and the fact that low quality drugs are able to infiltrate into the supply chain. In addition, this research has drawn attention to the issue of substandard drug products, especially because of the potentially lethal nature of the infections that these products are being used to treat. The relevance of this work in relation to substandard medicines is confirmed by Kaltenboeck et $\mathrm{al}^{53}$ who have reviewed the literature on the use of imatinib in the treatment 
of chronic myeloid leukemia. In assessing whether the literature provides evidence of the safety and efficacy of generic imatinib, their findings indicate that there are significant gaps in interpretability and quality. This highlights a need for information, where the bioequivalence of the generic products is compared to that of the original medicines, and the greater need for pharmacovigilance to assess both the impact of these medicines and their effect on patient safety. Table 4 presents a summary of various analytical techniques that have been developed to discriminate between counterfeit and genuine products. Although these techniques have evolved over the past 10 years and are being applied very successfully in the developed countries, there are limitations in terms of cost and the sophistication of the technology in relation to both instrumentation and lack of an appropriately trained workforce in developing countries.

\section{Supply chain}

The complexity of the supply chain for pharmaceuticals has been identified as contributing to the market for counterfeit medicines. ${ }^{65}$ There is a requirement that the supply chain be fit for purpose to ensure the safe supply of medicines. This supply chain begins with the raw materials and ends with the finished product, delivered to the patients, ensuring that there has been no tampering, diversion, falsification, substitution, or adulteration. ${ }^{64}$ Pharmacists, because of the various positions that they hold in the supply chain and their expertise in drugs and drug products, are said to have a role to play in securing the supply chain. This has been highlighted by the call for updating training programs for pharmacists in India, with extension of their role to creating awareness among all health professionals. ${ }^{65}$ An innovative solution to decrease the complexity of the supply chain has been put forward by Cozella et $\mathrm{al}^{66}$ who proposed that drug packaging security be achieved by the application of white light speckle theory to an ultraviolet (UV) source linking packaging to a barcode. Both direct and indirect technology may be used to optimize the security of packaging. Direct technology offers the consumer the opportunity to visually inspect the packaging and includes such techniques as holograms and color shift inks. Barcodes and RFID allow electronic control of the products within the sale system. RFID could be used in developing countries, even accounting for poor electricity supply by integration with cell phones. Indirect technology however is reliant on expertise, dedicated instrumentation, and is characterized by its invisibility and includes the use of UV inks, color, and UV microtext print taggant and laser surface authentication. Physical unclonable function (PUF) involves the inclusion of chemical particles randomly into packaging, with white light speckle as a PUF being put forward as an alternative to a laser speckle method. This is advantageous as PUF only requires incoherent light illumination, with a surface with speckle-like reflectivity applied by spraying with retroreflective paint. ${ }^{66}$

\section{Conclusion}

Drugs make an essential contribution to the quality of life, human dignity, and self-esteem of populations worldwide and are significant to people being employed and the subsequent economic and social upliftment of entire populations, especially in the developing world. Although counterfeit drugs present a global problem, there is however a vast difference between the nature of the drugs counterfeited in developing countries and those in developed countries. Primarily expensive lifestyle drugs such as sildenafil and tadalafil are counterfeited in the developed world, while those drugs frequently counterfeited in developing countries are to treat life threatening diseases such as malaria, tuberculosis, HIV/ AIDS, and other serious infectious conditions. Kelesidis et $\mathrm{al}^{67}$ in their review of the scientific evidence on counterfeit or substandard antimicrobial drugs have highlighted the consequences for patients and society of these low quality antimicrobials. Although challenges worldwide include the increasing sophistication of the counterfeiters, the lack of an international "fake" drug treaty, the lack of laws to pursue the counterfeiters of drugs (with these laws in place for other intellectual property infringements), and the expansion of counterfeiting to all therapeutic fields including expensive cancer medicines, there is an increased level of complexity to resolving this issue in the developing world. Essential drugs are important to public health programs, aimed at reducing mortality and morbidity in the developing world, where poor quality and counterfeit drugs represent only one of the issues associated with the lack of accessibility to drugs for these populations. A lack of access, which is attributed to economic reasons, is yet another factor which divides the developed and developing world and has resulted in an increase in counterfeit products in developing countries over the past 10 years, providing a very fertile market of desperate, uninformed, and unsophisticated people.

As early as 1997 , Shakoor et $\mathrm{l}^{68}$ reported on the need to assess the incidence of substandard drugs in developing countries, which is prevalent due to poor regulation and control in these drugs, unlike in the developed world. As a result it might be difficult to distinguish whether increasing drug resistance is due to counterfeit or substandard medicines, or both. In these developing 
countries, if a product fails a pharmacopoeial test, it cannot be assumed that it is counterfeit, with a lack of good manufacturing practice, adequate quality assurance and drug degradation, or decomposition due to inappropriate packaging and storage all potential contributors to the substandard quality of these products. This was again addressed by Ravinetto et al ${ }^{69}$ after almost 15 years, who reported that although there have been a number of initiatives globally attempting to address counterfeit medicines, the issue of substandard medicines has been neglected and in the developing world these medicines are not only widespread, but are as dangerous as counterfeits. Tremblay ${ }^{64}$ concurs with these findings identifying that the complexity related to counterfeiting is due to the consumer not being informed, the Internet exacerbating the problem, the criminal element associated with counterfeiting, and the fact that substandard medicines may be a bigger problem. While much effort has been focused on the development of sophisticated analytical methods to detect counterfeit drugs, these methods are only really applicable in the developed world. It is hoped that measures will also be put in place to address this real public health problem and to prevent the appearance of poor quality products, whether medicines or devices, to protect the interests of patients worldwide, especially those most vulnerable in the developing countries.

\section{Disclosure}

The author reports no conflict of interest in this work.

\section{References}

1. Staake T, Thiesse F, Fleisch E. Business strategies in the counterfeit market. J Bus Res. 2012;65:658-665.

2. World Health Organization. General Information on Counterfeit Medicines [webpage on the Internet]. Available from: http://www.who.int/ medicines/services/counterfeit/overview/en/. Accessed September 30, 2013.

3. Sulaiman SM, Traoŕe M, Engels D, Hagan P, Cioli D. Counterfeit praziquantel. Lancet. 2001;358:666-667.

4. World Health Organization. Substandard and Counterfeit Medicines [webpage on the Internet]. Available from: http://www. who.int/mediacentre/factsheets/2003/fs275/en/. Accessed September 30, 2013.

5. Bate R, Ginger ZJ, Mathur A. Does price reveal poor-quality drugs? Evidence from 17 countries. J Health Econ. 2011;30:1150-1163.

6. Furnham A, Valgeirsson $H$. The effect of life values and materialism on buying counterfeit products. J Socio Econ. 2007;36:677-685.

7. Stumpf SA, Chaudhry P. Country matters: Executives weigh in on the causes and counter measures of counterfeit trade. Business Horizons. 2010;53:305-314.

8. Newton PN, Green MD, Fernández M. Impact of poor quality medicines in the developing world. Trends Pharmacol Sci. 2010;31:99-101.

9. Delpierre A, Gayot A, Carpentier A. Update on counterfeit antibiotics worldwide; Public health risks. Med Mal Infect. 2012;42:247-255.
10. Nair A, Strauch S, Lauwo J, Jähnke RW, Dressman J. Are counterfeit or substandard anti-infective products the cause of treatment failure in Papua New Guinea? J Pharm Sci. 2011;100:5059-5068.

11. Newton PN, Green MD, Fernández FM, Day NP, White NJ. Counterfeit anti-infective drugs. Lancet Infect Dis. 2006;6:602-613.

12. Dégardin K, Roggo Y, Margot P. Understanding and fighting the medicine counterfeit market. J Pharm Biomed Anal. 2014;87:167-175.

13. Almuzaini T, Choonara I, Sammons H. Substandard and counterfeit medicines: a systematic review of the literature. BMJ Open. 2013;3: e002923.

14. Foster S. Supply and use of essential drugs in Sub-saharan Africa: some issues and possible solutions. Soc Sci Med. 1991;32:1201-1281.

15. World Health Organization. Counterfeit medicines. In: WHO Expert Committee on Specifications for Pharmaceutical Preparations. Geneva: World Health Organization; 2009:17-20. Available from: http://whqlibdoc.who. int/trs/WHO_TRS_953_eng.pdf. Accessed October 2, 2013.

16. Wertheimer AI, Norris J. Safeguarding against substandard/counterfeit drugs: mitigating a macroeconomic pandemic. Res Social Adm Pharm. 2009;5:4-16.

17. Hanif M, Mobarak MR, Ronan A, Rahman D, Donovan JJ Jr, Bennish ML. Fatal renal failure caused by diethylene glycol in paracetamol elixir: the Bangladesh epidemic. BMJ. 1995;311:88-91.

18. Okeke IN, Lamikanra A, Edelman R. Socioeconomic and behavioural factors leading to acquired bacterial resistance to antibiotics in developing countries. Emerg Infect Dis. 1999;5:18-27.

19. Lon CT, Tsuyuoka R, Phanouvong S, et al. Counterfeit and substandard antimalarial drugs in Cambodia. Trans R Soc Trop Med Hyg. 2006;100: 1019-1024.

20. Myint HY, Tipmanee P, Nosten F, et al. A systematic overview of published antimalarial drug trials. Trans R Soc Trop Med. 2004;98: 73-81.

21. Newton PN, Dondorp A, Green M, Mayxay M, White NJ. Counterfeit artesunate antimalarials in southeast Asia. Lancet. 2003;362:169.

22. Newton PN, White NJ, Rozendaal JA, Green MD. Murder by fake drugs - time for international action. BMJ. 2002:324:800-801.

23. Cui L, Yan G, Sattabongkot J, et al. Malaria in the Greater Mekong Subregion: heterogeneity and complexity. Acta Trop. 2012;121: 227-239.

24. Nayyar GML, Breman JG, Newton PN, Herrington J. Poor-quality antimalarial drugs in southeast Asia and sub-Saharan Africa. Lancet Infect Dis. 2012;12:488-496.

25. Ricci C, Nyadong L, Yang F. Assessment of hand-held Raman instrumentation for in-situ screening for potentially counterfeit artesunate antimalarial tablets by FT-Raman spectroscopy and direct ionization mass spectrometry. Anal Chim Acta. 2008;623:178-186.

26. Green MD, Nettey H, Villalva Rojas O, et al. Use of refractometry and colorimetry as field methods to rapidly assess antimalarial drug quality. J Pharm Biomed Anal. 2007;43:105-110.

27. Ahmad K. Antidepressants are sold as antiretrovirals in DR Congo. Lancet. 2004;363:713.

28. Fears R, Kaufmann S, ter Meulen V, Zumla A; EASAC Working Group. Drug resistant tuberculosis in the European Union: opportunities and challenges for control. Tuberculosis (Edinb). 2012;90:182-187.

29. Over $8 \%$ of medical devices in circulation are counterfeit: WHO [webpage on the Internet]. Available from: http://www.news-medical. net/news/20100128/Over-825-of-medical-devices-in-circulation-arecounterfeit-WHO.aspx. Accessed October 4, 2013.

30. Mori M, Ravinetto R, Jacobs J. Quality of medical devices and in vitro diagnostics in resource-limited settings. Trop Med Int Health. 2011;16:1439-1449.

31. Liu KY, Lam DS. Direct measurement of micro-keratomes gap width by electron microscopy. J Cataract Refract Surg. 2001;27:924-927.

32. Bimenya GS, Nzarubara GR, Kiconco J, Sabuni S, Byarugaba W. The accuracy of self monitoring blood glucose meter systems in Kampala Uganda. Afr Health Sci. 2003;3:23-32.

33. Day JN, Hien TT, Farrar J. Expiry date tampering. Lancet. 2004; $363: 172$. 
34. Arya SC, Agarwal N, Agarwal S. Comparison of two amoxicillin/ clavulanic acid-resistant profiles employing two types of assay disks: A pilot study in 50 isolates from a tertiary care hospital in India. Current Therapeutic Research. 2006;67:151-156.

35. Volkow P, Sandoval S, Campos AM, et al. Increase in catheter insertion-site infection associated to the introduction of a substandard competitive antiseptic. Am J Infect Control. 2006;34:335-337.

36. Souza Antunes AL, Secchi C, Reiter KC, et al. Evaluation of oxacillin and cefoxitin disks for detection of resistance in coagulase negative staphylococci. Mem Inst Oswalso Cruz. 2007;102:719-723.

37. Gordon C, Van Deun A, Lumb R. Evaluating performance of basic fuchsin for Ziehl-Neelsen stain. Int J Tuberc Lung Dis. 2009;13: 130-135.

38. Petti CA, Polage CR, QuinnTC, Ronald AR, Sande MA. Laboratory medicine in Africa: a barrier to effective health. Clin Infect Dis. 2006;42:377-382.

39. Seear M. Pharmaceutical quality: an urgent and unresolved issue. Lancet Infect Dis. 2012;12:428-429.

40. World Health Organization. Counterfeit drugs. Guidelines for the development of measures to combat counterfeit medicines. Geneva: World Health Organization; 1999. Available from: http://www.who.int/ medicines/publications/counterfeitguidelines/en/\#. Accessed October 5, 2013.

41. Counterfeit drugs: a growing global threat. Lancet. 2012;379:685.

42. Bate R, Attaran A. A counterfeit drug treaty: great idea, wrong implementation. Lancet. 2010;376:1446-1448.

43. Shashikant S. QSE Working Group divided, IMPACT secretariat moves to Italy [webpage on the Internet]. Available from: http://www.twnside. org.sg/title2/intellectual_property/info.service/2011/ipr.info.110302. htm. Accessed November 24, 2013.

44. Hermann RM. World Health Assembly: members gavel new mechanisms to fight poor-quality medicines [webpage on the Internet]. Available from: http://www.ip-watch.org/2012/05/26/world-health-assemblymembers-gavel-new-mechanism-to-fight-poor-quality-medicines/. Accessed November 24, 2013.

45. International Regulatory Harmonization. International conference of drug regulatory attitudes. WHO Drug Information. 2012;26:339-352.

46. Global Forum on Law, Justice and Development. Counterfeit medicines: impact and potential solutions. Available from: http://globalforumljd. org/docs/events/100212_CounterfeitMedicines.pdf. Accessed November 24, 2013.

47. Appiah B. US Pharmacopoeia fighting counterfeit medicines in Africa. CMAJ. 2013;185:E666.

48. Mori AT, Kaale EA, Risha P. Reforms: a quest for efficiency or an opportunity for vested interests? A case study of pharmaceutical policy reforms in Tanzania. BMC Public Health. 2013;13:651.

49. Mackey TK, Liang BA. Improving global health governance to combat counterfeit medicines: a proposal for UNODC-WHO-Interpol trilateral mechanism. BMC Med. 2013;11:233.

50. United Nations Office on Drugs and Crime. How UNODC deals with HIV/AIDS. Vienna: UNODC HIV/AIDS Unit; 2006. Available from: http://www.unodc.org/documents/afghanistan//Health_HIV-AIDS/ HIV_UNODC_2pager.pdf. Accessed February 27, 2014.

51. Agbaraji EC, Ochulor DO, Ezeh GN. Food and drug counterfeiting in the developing nations: The implications and way-out. Academic Research International. 2012;3:24-31.
52. Bate R, Mooney L, Milligan J. The danger of substandard drugs in emerging markets: an assessment of basic product quality. Pharmacologia. 2012;3:46-51.

53. Kaltenboeck A, Long G, Hayes-Larson E, Lopes Gde L. Assessing the impact of substandard copy medicines in developing countries: the experience with imatinib copies. Expert Rev Clin Pharmacol. 2013;6: 691-701.

54. Said MM, Gibbons S, Moffat AC, Zloh M. Near-infrared spectroscopy (NIRS) and chemometric analysis of Malaysian and UK paracetamol tablets: a spectral database study. Int J Pharm. 2011;415:102-109.

55. Rodionova OY, Pomerantsev AL. NIR-based approach to counterfeitdrug detection. Trends Analyt Chem. 2010;29:795-803.

56. Dowell FE, Maghirang EB, Fernandez FM, Newton PN, Green MD. Detecting counterfeit antimalarial tablets by near-infrared spectroscopy. J Pharm Biomed Anal. 2008;48:1011-1014.

57. Marini RD, Rozet E, Montes ML, et al. Reliable low-cost capillaryelectrophoresis device for drug quality control and counterfeit medicines. J Pharm Biomed Anal. 2010;53:1278-1287.

58. Gaudiano MC, Di Maggio A, Antoniella E, et al. An LC method for the simultaneous screening of some common counterfeit and substandard antibiotics: Validation and uncertainty estimation. J Pharm Biomed Anal. 2008;48:303-309.

59. Guadiano MC, Antoniella E, Bertocchi P, Valvo L. Development and validation of a reverse-phase LC method for analysing potentially counterfeit antimalarial medicines. J Pharm Biomed Anal. 2006;42: $132-135$.

60. $\mathrm{Hu} \mathrm{CQ}, \mathrm{Zou} \mathrm{WB}, \mathrm{Hu} \mathrm{WS}$, et al. Establishment of a Fast Chemical identification system for screening of counterfeit drugs of macrolide antibiotics. J Pharm Biomed Anal. 2006;40:68-74.

61. Deconinck E, Canfyn M, Sacré PY, Courselle P, De Beer JO. Evaluation of residual solvent content of counterfeit tablets and capsules. J Pharm Biomed Anal. 2013;81-82:80-88.

62. Kwok K, Taylor LS. Analysis of the packaging enclosing a counterfeit pharmaceutical tablet using Raman microscopy and two-dimensional correlation spectroscopy. Vib Spectrosc. 2012;61:176-182.

63. Rodomonte AL, Guadiano MC, Antoniella E, et al. Counterfeit drugs detection by measurement of tablets and secondary packaging colour. J Pharm Biomed Anal. 2010;53:215-220.

64. Tremblay M. Medicines counterfeiting is a complex problem: A review of key challenges across the supply chain. Curr Drug Saf. 2013;8:43-55.

65. Rajapandian G, Narayanan N, Maheswaran A, Chanchal P. Dangerous world of counterfeit drugs-Pharmacist's role and its prevention. Int J Pharm Sci Rev Res. 2013;4:1709-1713.

66. Cozella L, Simonetti C, Spagnolo GS. Drug packaging security by means of white-light speckle. Opt Lasers Eng. 2012;50:1359-1371.

67. Kelesidis T, Kelesidis I, Rafailidis PI, Falagas ME. Counterfeit or substandard antimicrobial drugs: a review of the scientific evidence. J Antimicrob Chemother. 2007;60:214-236

68. Shakoor O, Taylor RB, Behrens RH. Assessment of the incidence of substandard drugs in developing countries. Trop Med Int Health. 1997;2:839-845.

69. Ravinetto RM, Boelaert M, Jacobs J, Pouget C, Luyckx C. Poor-quality medical products: time to address substandards, not only counterfeits. Trop Med Int Health. 2012;17:1412-1416.
Research and Reports in Tropical Medicine

\section{Publish your work in this journal}

Research and Reports in Tropical Medicine is an international, peerreviewed, open access journal publishing original research, case reports, editorials, reviews and commentaries on all areas of tropical medicine, including: Diseases and medicine in tropical regions; Entomology; Epidemiology; Health economics issues; Infectious disease; Laboratory science and new technology in tropical medicine; Parasitology; Public health medicine/health care policy in tropical regions; and Microbiology. The manuscript management system is completely online and includes a very quick and fair peer-review system. Visit http://www.dovepress. com/testimonials.php to read real quotes from published authors. 